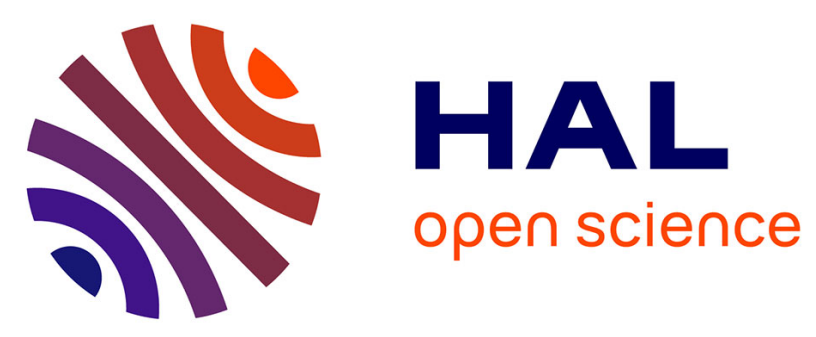

\title{
Line-shape parameters and their temperature dependences predicted from molecular dynamics simulations for O2-and air-broadened CO2 lines
}

H. T. Nguyen, N. H. Ngo, H. Tran

\section{- To cite this version:}

H. T. Nguyen, N. H. Ngo, H. Tran. Line-shape parameters and their temperature dependences predicted from molecular dynamics simulations for O2-and air-broadened CO2 lines. Journal of Quantitative Spectroscopy and Radiative Transfer, 2020, 242, pp.106729. 10.1016/j.jqsrt.2019.106729 . hal-02500553

\section{HAL Id: hal-02500553 \\ https://hal.sorbonne-universite.fr/hal-02500553}

Submitted on 6 Mar 2020

HAL is a multi-disciplinary open access archive for the deposit and dissemination of scientific research documents, whether they are published or not. The documents may come from teaching and research institutions in France or abroad, or from public or private research centers.
L'archive ouverte pluridisciplinaire HAL, est destinée au dépôt et à la diffusion de documents scientifiques de niveau recherche, publiés ou non, émanant des établissements d'enseignement et de recherche français ou étrangers, des laboratoires publics ou privés. 


\title{
Line-shape parameters and their temperature dependences predicted from molecular dynamics simulations for $\mathrm{O}_{2}$ - and air-broadened $\mathrm{CO}_{2}$ lines
}

\author{
H. T. Nguyen ${ }^{1,2,3}$, N. H. Ngo ${ }^{1, *}$ and H. Tran ${ }^{2, \dagger}$ \\ ${ }^{1}$ Faculty of Physics, Hanoi National University of Education, 136 Xuan Thuy, Cau Giay, \\ Hanoi, Vietnam \\ ${ }^{2}$ Laboratoire de Météorologie Dynamique, IPSL, CNRS, Sorbonne Université, École normale \\ supérieure, PSL Research University, École polytechnique, F-75005 Paris, France \\ ${ }^{3}$ REMOSAT, University of Science and Technology of Hanoi (USTH), Vietnam Academy of \\ Science and Technology (VAST)
}

\begin{abstract}
Requantized classical molecular dynamics simulations (rCMDS) were performed for $\mathrm{CO}_{2}$ highly diluted in $\mathrm{O}_{2}$ at 200,250,296 and $350 \mathrm{~K}$ using a site-site intermolecular potential. The simulations were made for $0.5 \mathrm{~atm}$ of $\mathrm{O}_{2}$ pressure and for a large range of Doppler widths, covering near-Doppler regime to collisional-dominant regime. The Fourier-Laplace transform of the auto-correlation functions of the dipole moment, calculated by rCMDS, leads to the associated spectra of $\mathrm{CO}_{2}$ broadened by $\mathrm{O}_{2}$. Different effects of collisions between $\mathrm{CO}_{2}$ and $\mathrm{O}_{2}$ molecules are included in the simulated spectra. In order to determine the profile parameters of $\mathrm{O}_{2}$-broadened $\mathrm{CO}_{2}$ lines, the rCMDS-calculated spectra were fitted with the speed-dependent Nelkin-Ghatak profile associated with the first-order line mixing. The collisional line broadening coefficient, its speed dependence component, the Dicke narrowing and the firstorder line-mixing parameters were retrieved for lines with $J$ up to 50 and for all considered temperatures. The temperature dependences of these line-shape parameters were then deduced using the usual single power law. From results obtained in this work and those obtained for $\mathrm{CO}_{2}$ in $\mathrm{N}_{2}$ [Nguyen et al, J Chem Phys, 149, 224301, 2018], the air-broadened line-shape parameters and their temperature dependences for $\mathrm{CO}_{2}$ lines were calculated and compared with literature data showing very good agreement.
\end{abstract}

Keywords: Molecular dynamics simulations, $\mathrm{rCMDS}, \mathrm{O}_{2}$-broadened $\mathrm{CO}_{2}$, line shape, line mixing, speed-dependent Nelkin-Ghatak profile, speed dependence, Dicke narrowing

\section{Introduction}

Carbone dioxide $\left(\mathrm{CO}_{2}\right)$ is one of the most abundant elements in the Earth's atmosphere, the second greenhouse gas after atmospheric water. Measuring the atmospheric $\mathrm{CO}_{2}$ columns with high precision and high accuracy in order to understand $\mathrm{CO}_{2}$ source and sink processes is the objective of several space-born (e.g. [1-4]) experiments. To this aim, an uncertainty below $1 \mathrm{ppm}(0.3 \%)$ is needed for the retrieved atmospheric $\mathrm{CO}_{2}$ columns [5,6]. The latter are retrieved by minimizing the difference between the measured spectra and those calculated using a forward model based on the knowledge of the spectroscopy of $\mathrm{CO}_{2}$ and interfering gases. The precision requirement of atmospheric remote sensing studies thus puts very severe constraints on the quality of the $\mathrm{CO}_{2}$ spectroscopic data (i.e. line position, line intensity and line profile) needed for the forward calculations. It is now well known that one has to take into account

\footnotetext{
* Corresponding author: hoa.nn@hnue.edu.vn

† Corresponding author: ha.tran@1md.jussieu.fr
} 
refined collisional effects on the spectral profile in order to accurately model the measured lines and to achieve the per mill precision requirement of applications (see [7] and references therein). These effects include the collisions-induced line mixing, the molecular speed dependences of the collisional line broadening and shifting, the collisions-induced velocity changes. Many laboratory studies were devoted to the precise determination of line-shape parameters for $\mathrm{CO}_{2}$ (e.g. [8-14]). In these works, line-shape parameters were generally retrieved from high quality spectra measured under various pressure conditions, using a multi-spectrum fitting procedure [15]. In parallel, it was recently shown that line-shape parameters for linear molecules can be predicted using requantized classical molecular dynamics simulations (rCMDS) [16,17]. Indeed, in these rCMDS, one can simulate the time evolution of a very large number of molecules from an intermolecular potential. The auto-correlation function of the dipole moment, responsible for the optical transition can thus be calculated. The FourierLaplace transform of this auto-correlation function directly yields the corresponding absorption spectrum. It was demonstrated in a series of papers that rCMDS are capable to reproduce various collisional effects affecting the absorption spectrum of different molecular systems [1627]. In a recently published paper [16], rCMDS were used to predict line-shape parameters for $\mathrm{N}_{2}$-broadened $\mathrm{CO}_{2}$ lines. To this aim, the rCMDS-calculated spectra of $\mathrm{CO}_{2}$ in $\mathrm{N}_{2}$ were fitted with the speed-dependent Nelkin-Ghatak (sdNG) profile in order to retrieve the collisional line broadening coefficient, its speed dependence, the Dicke narrowing and the first-order linemixing parameters. The predicted parameters were then compared with those determined from high quality measurements [14] showing very good agreement, even for the high-order lineshape parameters [16]. rCMDS are thus a complementary tool for line-shape studies provided that an accurate intermolecular potential is available. Furthermore, the calculations can be performed relatively easily for various temperature conditions, which is not always possible for laboratory measurements. As a follow up to the study of [16], in this paper, rCMDS are used to predict line-shape parameters for $\mathrm{O}_{2}$-broadened $\mathrm{CO}_{2}$ lines.

This paper is organized as follows: In Sec. 2 the rCMDS calculations used for $\mathrm{CO}_{2}$ diluted in $\mathrm{O}_{2}$ are described as well as the analysis procedure of the simulated spectra. The predicted parameters for $\mathrm{O}_{2}$-broadened $\mathrm{CO}_{2}$ but also for $\mathrm{CO}_{2}$ in air, computed from those of $\mathrm{CO}_{2}$ in $\mathrm{O}_{2}$ and of $\mathrm{CO}_{2}$ in $\mathrm{N}_{2}$ are presented and compared with literature data in Sec. 3 while the conclusion and perspectives of this work are summarized in Sec. 4.

\section{Classical molecular dynamics simulations for $\mathrm{CO}_{2}-\mathrm{O}_{2}$ and analysis procedure}

Calculations were made for four temperatures 200, 250, 296 and $350 \mathrm{~K}$ at $1 \mathrm{~atm}$ for $\mathrm{CO}_{2}-\mathrm{O}_{2}$ mixtures with $50 \%$ of $\mathrm{CO}_{2}$ using the IBM Blue Gene/P computer of the Institut $d u$ Développement et des Ressources en Informatique Scientifique but also the facilities of the faculty of physics at Hanoi National University of Education. Only $\mathrm{CO}_{2}-\mathrm{O}_{2}$ interactions being taken into account, this is equivalent to $\mathrm{CO}_{2}$ infinitely diluted in $0.5 \mathrm{~atm}$ of $\mathrm{O}_{2}$. Details on the calculations method can be found in [16] and references therein. A site-site functional form with Coulombic and atom-atom contributions was used to describe the interaction potential between $\mathrm{CO}_{2}$ and $\mathrm{O}_{2}$ molecules. For that, the molecular geometries, the charges and sites were taken from [28] and [29] for $\mathrm{CO}_{2}$ and $\mathrm{O}_{2}$, respectively. The atom-atom contribution was calculated as a 12-6 Lennard-Jones potential whose parameters were deduced using usual combination laws [30] and parameters for $\mathrm{CO}_{2}-\mathrm{CO}_{2}$ [28] and $\mathrm{O}_{2}-\mathrm{O}_{2}$ [29] interactions. These potentials for $\mathrm{CO}_{2}-\mathrm{CO}_{2}$ and $\mathrm{O}_{2}-\mathrm{O}_{2}$ were successfully used to predict non-Voigt effects on the line shapes of pure $\mathrm{CO}_{2}$ (e.g. [19]) and $\mathrm{O}_{2}$ in air (e.g. [17]), respectively. The molecules were considered as rigid rotors and all the effects of vibrational motion were disregarded in the calculations. Note that our rCMDS do not take into account the dephasing of the dipole, which 
is associated with the fact that the effects of intermolecular interactions for molecules in the upper and lower states of the optical transitions are different. Consequently, the calculated spectra do not show any pressure shift.

For each temperature, a total number of about $3 \times 10^{8}$ molecules was considered. The molecules were treated in parallel in more than fifteen thousand boxes, each containing 20000 molecules. The molecules were randomly initialized in the boxes with translational and angular speeds verifying the Maxwell-Boltzmann distribution. Random center-of-mass velocity vector and molecular axis orientation were attributed. The parameters (center-of-mass position, velocity, angular momentum, and molecular orientation) describing the classical state of each molecule were then computed for each time step. A requantization procedure, as done in $[16,18]$ for pure $\mathrm{CO}_{2}$ and for $\mathrm{CO}_{2}$ in $\mathrm{N}_{2}$, was applied to the classical rotation of the molecules. Specifically, for a molecule of rotational angular speed $\omega$, we find the (even) integer $J$ for which $\hbar J / I$, where $I$ is the moment of inertia, is the closest to $\omega$. This corresponds to matching the classical rotational frequency with the quantum position of the $\mathrm{P}$ branch lines. Once $J$ is found, $\omega$ is requantized by applying the change $\omega=\hbar J / I$ while the orientation of the rotational angular momentum is kept unchanged. This $\mathrm{P}$ branch requantization implies that the calculated $\mathrm{R}$ branch spectrum will be the exact symmetric of the $\mathrm{P}$ branch. The auto-correlation function of the dipole moment, assumed along the molecular axis (as the case for the asymmetric stretching absorption bands of $\mathrm{CO}_{2}$, for instance), was then calculated during the requantized CMDS (rCMDS). The Doppler effect associated to the translational motion was taken into account in this auto-correlation function. For each temperature, eight values of the Doppler width $\Gamma_{D}$ (ranging from about $0.002 \mathrm{~cm}^{-1}$ to $0.3 \mathrm{~cm}^{-1}$ ) were used in the calculations. This provided a large set of values of the ratio $\Gamma_{L} / \Gamma_{D}$ (from about 0.08 to $13, \Gamma_{L}$ being the Lorentz width), covering a range from the near purely Doppler to collision-dominant regimes. Since all the effects of vibrational motion were disregarded in our rCMDS, this corresponds to eight calculations at eight values of pressure with a unique Doppler width. Finally, the absorption coefficient was obtained as the Fourier-Laplace transform of the auto-correlation function of the dipole moment. The spectra were thus calculated without the use of any adjustable parameter.

rCMDS were also performed for $\mathrm{CO}_{2}$ in $\mathrm{N}_{2}$ at $250 \mathrm{~K}$, using the same calculations procedure as in our previous work devoted to $\mathrm{CO}_{2} / \mathrm{N}_{2}$ [16]. In the latter, only two temperature conditions were considered, i.e. 200 and $296 \mathrm{~K}$. The use of this calculation in addition to those of [16] allows to improve the precision of the predicted temperature dependences of $\mathrm{CO}_{2} / \mathrm{N}_{2}$ line-shape parameters. The results obtained for $\mathrm{CO}_{2} / \mathrm{N}_{2}$ and those for $\mathrm{CO}_{2} / \mathrm{O}_{2}$ will be used in this work to deduce the air-broadened $\mathrm{CO}_{2}$ line-shape parameters and their temperature dependences.

As for the case of $\mathrm{CO}_{2} / \mathrm{N}_{2}$ [16], the rCMDS-calculated spectra for each temperature were fit with the speed-dependent Nelkin-Ghatak (sdNG) profile including the first-order line mixing [31]. As well known (see [32] and references therein), this profile takes into account the Doppler effect, the collisional broadening, its speed dependence and the collisions-induced velocity changes. For each considered temperature, the Doppler broadening $\Gamma_{D}$ is fixed to values used in the rCMDS. The speed-dependent collisional half-with, $\Gamma(v)$, is modeled using the quadratic law [33,34], i.e. $\Gamma(v)=\Gamma_{0}+\Gamma_{2}\left[(v / \tilde{v})^{2}-3 / 2\right]$ in which $\tilde{v}=\sqrt{2 k_{B} T / m}$ is the most probable speed for an absorbing molecule of mass $m$. The (thermally averaged) line width, $\Gamma_{0}$ and its speed dependence component, $\Gamma_{2}$, both in $\mathrm{cm}^{-1}$, are adjusted in the fits. The collision-induced velocity changes (VC) effect is taken into account by using the hard-collision model $[35,36]$. Within this model, this effect is characterized by the velocity changing collisions rate $v_{v c}$ (or the Dicke narrowing frequency, in $\mathrm{cm}^{-1}$ ) which will be retrieved from the fits. Finally, the firstorder line-mixing parameter, $Y$ (no unit) accounting for the coupling between the considered line and the others, is also adjusted in the fits. 
A multi-spectrum fitting procedure, developed previously in our group (e.g. $[37,38]$ ) was used to retrieve the line-shape parameters. For a given temperature, spectra of the same line, calculated for various Doppler width values, were simultaneously adjusted, the line-shape parameters being constrained to be the same for all spectra. As mentioned previously, the pressure-shifting was fixed to zero since no pressure shift was taken into account in our rCMDS. For each line, the line-broadening coefficient $\gamma_{0}\left(\Gamma_{0} / P\right.$, in $\left.\mathrm{cm}^{-1} / \mathrm{atm}\right)$, its speed dependence component $\gamma_{2}\left(\Gamma_{2} / P\right.$, in $\left.\mathrm{cm}^{-1} / \mathrm{atm}\right)$, the Dicke narrowing parameter $\beta\left(v_{v c} / P\right.$, in $\left.\mathrm{cm}^{-1} / \mathrm{atm}\right)$ and the first-order line-mixing coefficient $\zeta\left(Y / P\right.$, in $\left.\mathrm{atm}^{-1}\right)$ were retrieved for each temperature. Their temperature dependences were then represented by the usual power law, i.e. $A(T)=$ $A\left(T_{0}\right)\left(\frac{T_{0}}{T}\right)^{n} A$, in which $T_{0}=296 \mathrm{~K}$ and $A(T)$ is either $\gamma_{0}, \gamma_{2}, \beta$ or $\zeta$ and $n_{A}$ is the temperature dependence exponent. The obtained results are presented in the next section.

\section{Results and discussions}

Figure 1 shows the simulated spectra of $\mathrm{CO}_{2}$ in $\mathrm{O}_{2}$ for the $\mathrm{P}(10)$ and $\mathrm{P}(20)$ lines for three different values of $\Gamma_{L} / \Gamma_{D}$ and at 200 and $296 \mathrm{~K}$ respectively. Residuals obtained from fitting these spectra with various line-shape models are shown in the lower panels. In addition to the sdNG profile, tests were also performed with more simplified models: the speed-dependent Voigt (sdV) (no Dicke narrowing effect), the Nelkin-Ghatak (NG) (no speed dependence effect) and the widely used Voigt (V) profiles. For all the used line profiles, line-mixing effect was taken into account. As can be observed on the examples of Fig. 1, the Voigt profile leads to the worse fits, with magnitude of fit residuals up to $3 \%$. The NG profile is in better agreement with the calculated spectra but significant structures remain in the fit residuals. Better fit residuals are obtained with the $\mathrm{sdV}$ and sdNG profiles. The remaining residuals are mainly due to the numerical noises in the rCMDS calculations. With respect to the sdV profile, the sdNG profile leads to slightly better residuals. This will explain the smallness and the large uncertainty of the retrieved Dicke narrowing parameters, presented in Sec. 3.3. Tests were also made with the Hartmann-Tran profile $[32,39]$ in which the correlation between velocity changes and internal state changes is also taken into account. However, the results show no improvement with respect to the sdNG profile. The sdNG model is thus retained for the analysis of the simulated spectra, as for the case of $\mathrm{CO}_{2}$ in $\mathrm{N}_{2}$ [16]. The retrieved line-shape parameters and their temperature dependences will be presented and compared with literature data in the next subsections. 

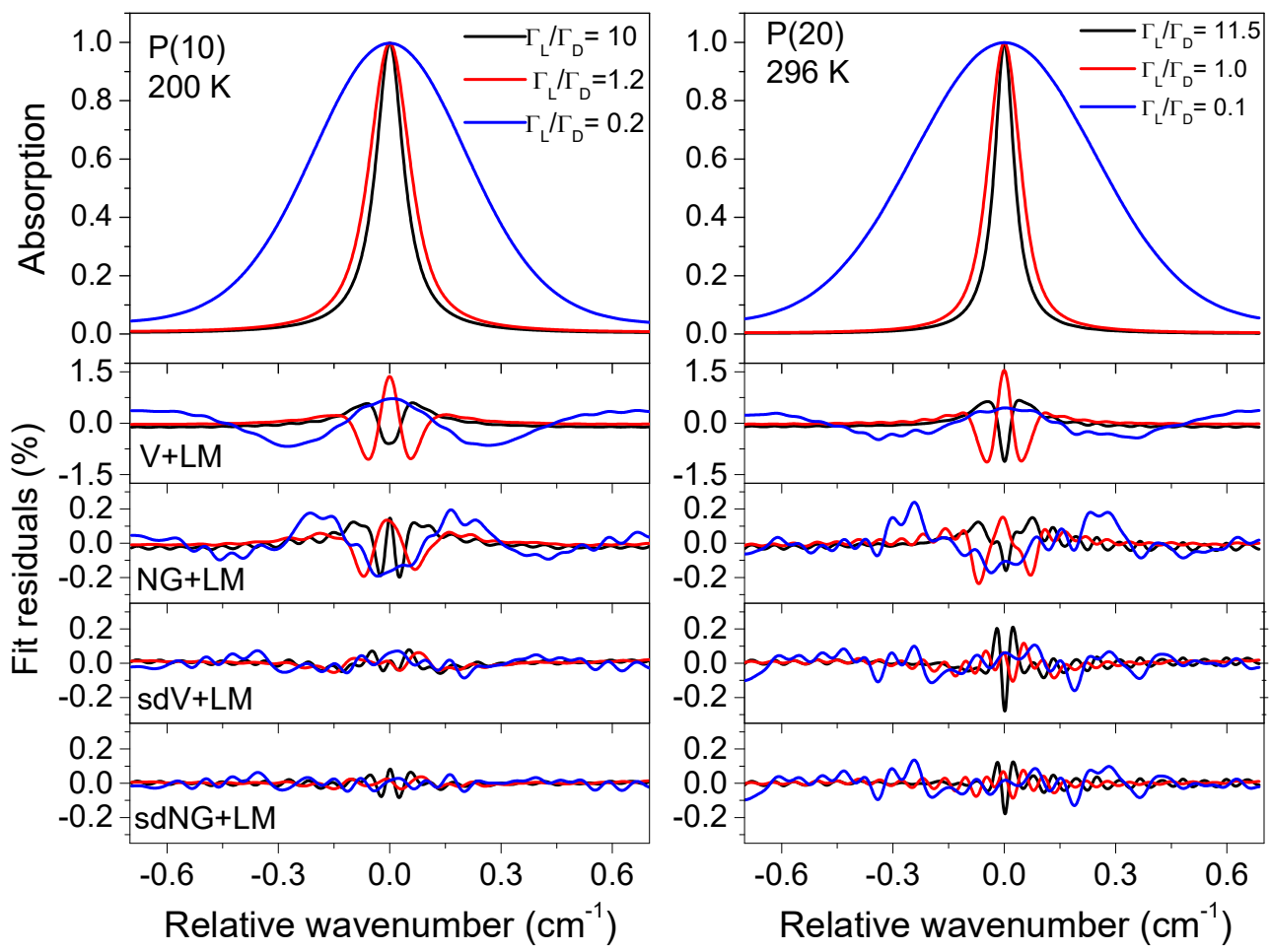

Fig. 1: rCMDS-calculated spectra for the $\mathrm{P}(10)$ and $\mathrm{P}(20)$ lines of $\mathrm{CO}_{2}$ broadened by $\mathrm{O}_{2}$ at $200 \mathrm{~K}$ and $296 \mathrm{~K}$, respectively and for different $\Gamma_{L} / \Gamma_{D}$ ratios, the $O_{2}$ pressure being $0.5 \mathrm{~atm}$. In the lower panels are the fit residuals obtained from multi-fitting these spectra with the Voigt (V), the Nelkin-Ghatak (NG), the speed-dependent Voigt (sdV) and the speed-dependent Nelkin-Ghatak (sdNG) profiles. Line-mixing effect was taken into account using the first-order approximation.

\subsection{The line-broadening coefficient and its temperature dependence}

The retrieved broadening coefficients for $\mathrm{O}_{2}$-broadened $\mathrm{CO}_{2}$ lines are presented in the right part of Fig. 2 versus the rotational quantum number $|m|(m=-J$ for P branch lines, $J$ being the rotational quantum number of the lower level of the line) for the four considered temperatures. Due to their weak signal-to-noise ratio, broadening coefficient for lines with $|\mathrm{m}|$ greater than 60 could not be determined. Several studies in the literature were devoted to the measurements of the $\mathrm{O}_{2}$-broadening coefficients of $\mathrm{CO}_{2}$ lines (see [40] and references therein). Most of them employed the Voigt profile to model the measured spectra, except [40] and [41]. In [40], the speed-dependent Voigt profile was used to retrieve the $\mathrm{O}_{2}$-broadened $\mathrm{CO}_{2}$ lineshape parameters in the $30013 \leftarrow 00001$ and $30012 \leftarrow 00001$ bands from high-resolution FTS spectra of $\mathrm{CO}_{2}$ lines. Hikida and Yamada [41] used the Galatry profile to determine $\mathrm{O}_{2}$ broadening coefficients for ten $\mathrm{CO}_{2}$ lines in the $30013 \leftarrow 00001$ band from diode laser measurements. It is well known that using the Voigt profile leads to smaller retrieved line broadening coefficients with respect to more refined line-shape models. Therefore, only [40] and [41] are retained here for comparison with our predicted results (left part of Fig. 2), both the measured and calculated values were obtained at room temperature. As can be observed, our predicted values are in rather good agreement with measured results, with an average difference of about $2 \%$, a very satisfying result for a classical method. 

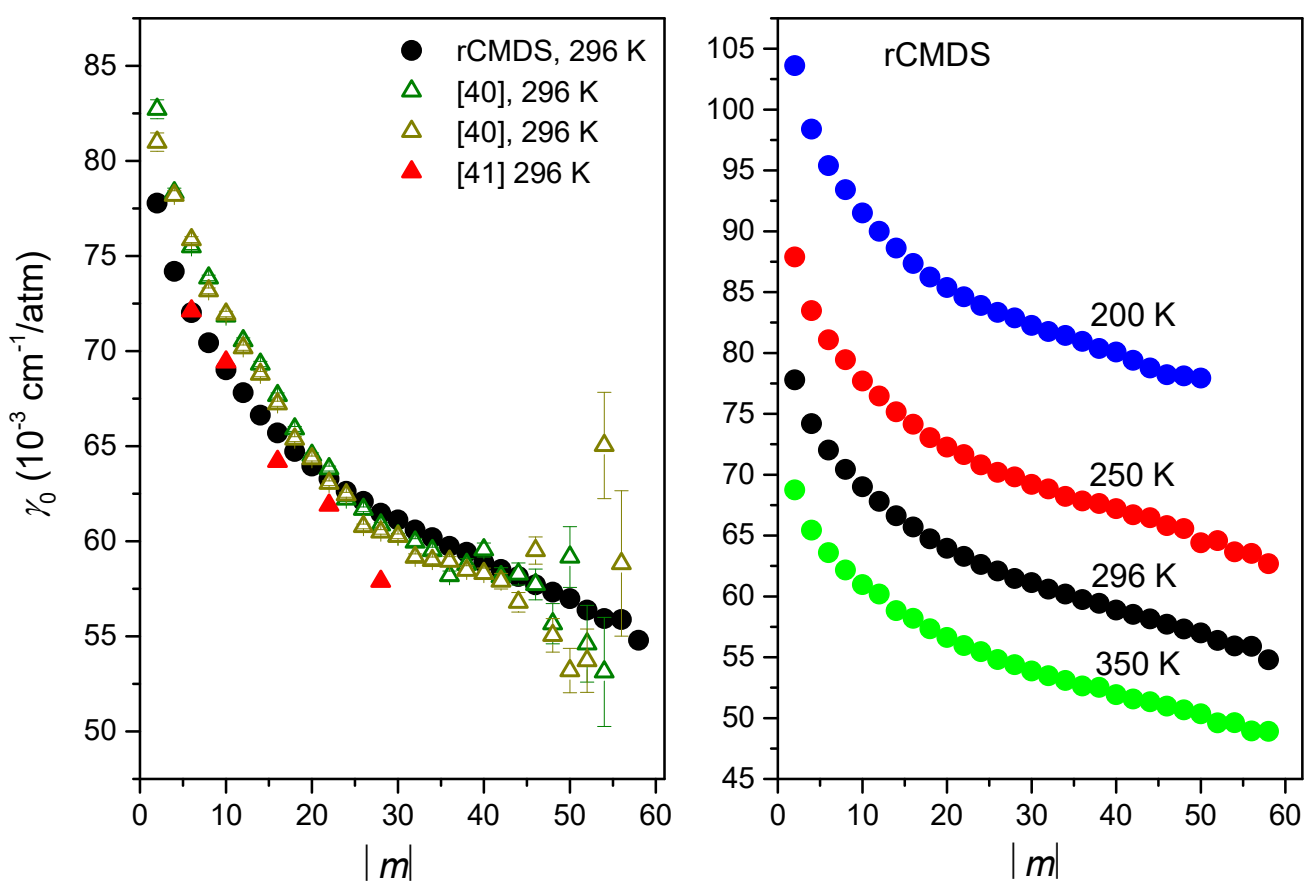

Fig. 2: Left panel: $\mathrm{O}_{2}$-broadening coefficients of $\mathrm{CO}_{2}$ lines deduced from fits of $r C M D S$-calculated spectra at $296 \mathrm{~K}$ (black circles) with the sdNG profile and comparison with measured values of [40] (olive and darkyellow triangles for the $30012 \leftarrow 00001$ and $30013 \leftarrow 00001$ bands, respectively) and [41] (red triangles) (see text).

Right panel: rCMDS-predicted broadening coefficients of $\mathrm{CO}_{2}$ in $\mathrm{O}_{2}$ at 200,250, 296 and $350 \mathrm{~K}$.

The predicted broadening coefficients for $\mathrm{CO}_{2} / \mathrm{O}_{2}$ at 200,250 and $296 \mathrm{~K}$ are then combined with those of $\mathrm{CO}_{2} / \mathrm{N}_{2}$ at the same temperature conditions (from [16] and this work) to deduce the air-broadening coefficients using $\gamma_{0}^{\text {air }}(T)=0.79 \gamma_{0}^{N 2}(T)+0.21 \gamma_{0}^{O 2}(T)$. Note that the fact that $\gamma_{0}^{N 2}$ are larger than $\gamma_{0}^{O 2}$ is well reproduced by rCMDS predictions (see also Fig. 2 of [16]). Figure 3 shows the obtained air-broadening coefficients for the three considered temperatures and their comparison with data of [11], [13] and of [12,42]. In those studies, airbroadening coefficients were determined from fits of measured spectra using the sdNG [13], the partially-correlated speed-dependent Nelkin-Ghatak (pcsdNG) [11] and the sdV [12,42] profiles. We can reasonably compare values of $\gamma_{0}$ obtained with these various speed-dependent profiles since, as demonstrated in $[9,43]$, the differences between values of $\gamma_{0}$ obtained with these speed-dependent profiles are very small, below 1\%. In [13] only the R(16) line of the $30013 \leftarrow 00001$ band was measured but for various temperatures. Values of $\gamma_{0}$ for 36 lines in the $30012 \leftarrow 00001$ band were measured in [11] at room temperature. In [12], lines of various vibrational bands in the $2.06 \mu \mathrm{m}$ spectral region were measured at various temperatures, only parameters of the most intense band $(20013 \leftarrow 00001)$ being shown here. Finally, [42] was devoted to the $(30013 \leftarrow 00001)$ band of $\mathrm{CO}_{2}$. Values of [13] and [12,42] at 250 and $200 \mathrm{~K}$ were deduced from the coefficients given at room temperature and the temperature dependence exponents. As shown in Fig. 3, a very good agreement between our predictions and these data can be observed. Most of the measured data are in good agreement with the predictions, except for values at low $|\mathrm{m}|$ where the difference between our prediction and measured values of [12] can be up to $5 \%$. These results confirms the quality of predictions using requantized CMDS and the associated intermolecular potential. 


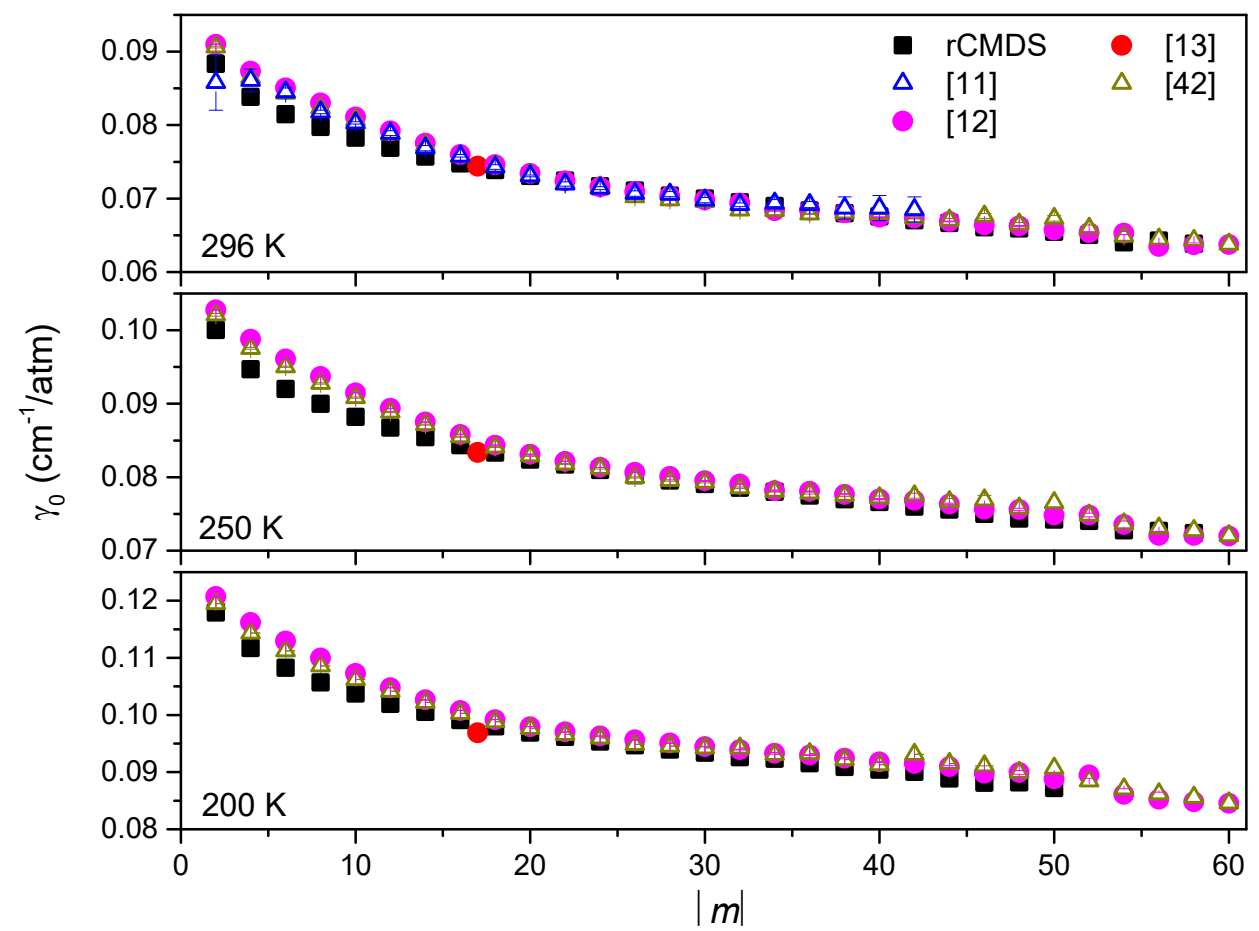

Fig.3: Air-broadening coefficients predicted by $r C M D S$ using results obtained here for $\mathrm{O}_{2}$-broadening and those for $\mathrm{N}_{2}$-broadening obtained in [16] and in this study, at 296, 250 and $200 \mathrm{~K}$. Results of [13], [11], and [12,42], obtained from fits of measured spectra with respectively, the $s d N G$, pcsdNG and $s d V$ profiles, are also displayed for comparison.

The temperature dependences for $\mathrm{O}_{2}$ - and air-broadening coefficients are determined using the usual power law (see Sec.2). The obtained results are displayed in Fig. 4, together with data for $\mathrm{CO}_{2}$ /air of [13] and $[12,42]$ but also those given in the 2016 edition of the HITRAN database [44]. For completeness, experimental values of [14] for $\mathrm{N}_{2}$-broadened $\mathrm{CO}_{2}$ lines in the $v_{3}$ band, obtained with the use of the sdNG profile, are also reported. For the predicted values, error bars obtained from the standard uncertainty of the fits $(1 \sigma)$ for the temperature exponents are also displayed. As can be seen on Fig. 4, our predicted values for $\mathrm{O}_{2}$ and air-broadening are quite close to each other, the maximum difference being for high $|m|$. For air-broadening, all the plotted data including the predicted ones are in good agreement, within $7-8 \%$. This demonstrates that rCMDS can be fully used to predict the temperature dependences of the broadening coefficients for molecular systems such as $\mathrm{CO}_{2}$. The rCMDS predicted values of $\gamma_{0}(296 \mathrm{~K})$ and $n_{\gamma_{0}}$ are listed in Table 1 and 2 for $\mathrm{O}_{2}$ - and air-broadening, respectively. 


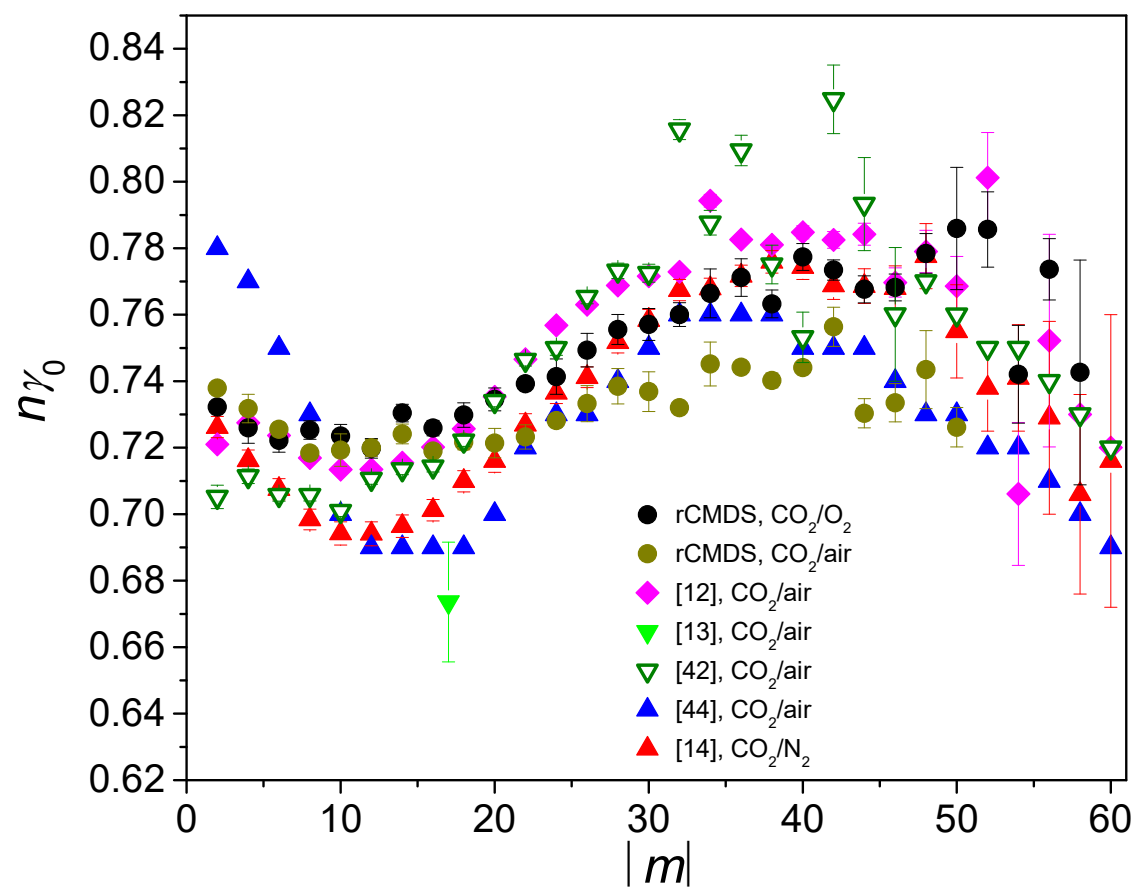

Fig. 4: The temperature exponents of $\mathrm{O}_{2^{-}}$(black circles) and air-broadening (olive circles) coefficients of $\mathrm{CO}_{2}$, deduced from rCMDS and comparison with those for $\mathrm{CO}_{2}$ in air of [12] (purple diamonds), [13] (green triangles), [42] (olive triangles) and [44] (blue triangles) and for $\mathrm{CO}_{2}$ in $\mathrm{N}_{2}$ of [14] (red triangles).

\subsection{The speed dependence of the line width and its temperature dependence}

Results for the predicted speed dependence parameters $\gamma_{2}$ for $\mathrm{O}_{2}$ - but also for airbroadening are presented in Fig. 5 for all considered temperatures. The ratios $\gamma_{2} / \gamma_{0}$ is plotted instead of $\gamma_{2}$. This allows for a straightforward comparison with literature data, since most of papers directly give this ratio. By combining the statistical uncertainty obtained from the fits and that due to the fitting technique (i.e. by changing the spectral range of the fits), we estimate a total uncertainty $(1 \sigma)$ of $5 \%$ for $\gamma_{2}$. Our results are compared with those of [40] for $\mathrm{O}_{2}-$ broadening and of $[11-13,42]$ for air. In [11], the ratio $\gamma_{2} / \gamma_{0}$ for air-broadening was assumed to be independent of the line (i.e. of $m$ ) and was obtained from fits of measured spectra of the $\mathrm{R}(16)$ line of the $30012 \leftarrow 00001$ band [10] with the pcsdNG profile at room temperature. The comparison in Fig. 5 shows that at $|m|=17$, the value of [11] is in good agreement with our result at room temperature but assuming $\gamma_{2} / \gamma_{0}$ independent of $m$ is probably too simplified. In [13], the same line but for the $30013 \leftarrow 00001$ band was investigated at various temperatures, using the sdNG profile. The retrieved value of $\gamma_{2} / \gamma_{0}$, independent of $\mathrm{T}$, is also in very good agreement with our predictions. Large differences with our results are observed when comparing to $[12,42]$ for $\mathrm{CO}_{2}$ in air and to [40] for $\mathrm{CO}_{2}$ in $\mathrm{O}_{2}$. These differences are due to the different line-shapes used in $[12,40,42]$ and in our work. $[12,40,42]$ used the speed-dependent Voigt profile while the speed-dependent Nelkin-Ghatak profile is used in the present work to retrieve line-shape parameters. The speed dependence parameter obtained with the sdV profile is usually larger than that obtained using the sdNG or HT profile, as observed in $[38,43,45,46]$ for instance. Note that in $[12,40,42]$, the ratio $\gamma_{2} / \gamma_{0}$ was assumed to be independent of $\mathrm{T}$, as in [13]. As shown in Fig. 5, the ratios $\gamma_{2} / \gamma_{0}$ predicted by rCMDS at different temperatures are quite close each other. This demonstrates that the temperature dependence of $\gamma_{2} / \gamma_{0}$ for $\mathrm{O}_{2}$ and air-broadening $\mathrm{CO}_{2}$ lines is relatively weak. In Refs. [13,43], it was shown that within the quadratic approximation for the speed-dependent broadening and the power law for the 
temperature dependence of the line broadening coefficient, $\gamma_{2} / \gamma_{0}$ is independent of temperature and can be given by [13]

$$
\frac{\gamma_{2}}{\gamma_{0}}=(1-n) \frac{2}{3} \frac{\frac{m_{p}}{m_{a}}}{1+\frac{m_{p}}{m_{a}}}
$$

In this equation, $n$ is the temperature exponent of $\gamma_{0}$ and $m_{a}, m_{p}$ are respectively the masses of the absorbing and perturbing molecules. The values of $n$ (Fig. 4) predicted by rCMDS were thus used to deduce $\gamma_{2} / \gamma_{0}$ using this relation. The obtained results for $\mathrm{O}_{2}$ - and air-broadening are shown in Fig. 5. As can be observed, it leads to rather good agreement with rCMDS results for $\mathrm{CO}_{2} / \mathrm{O}_{2}$ but for $\mathrm{CO}_{2} /$ air, Eq. (1) slightly underestimates the values of $\gamma_{2} / \gamma_{0}$ predicted by rCMDS.

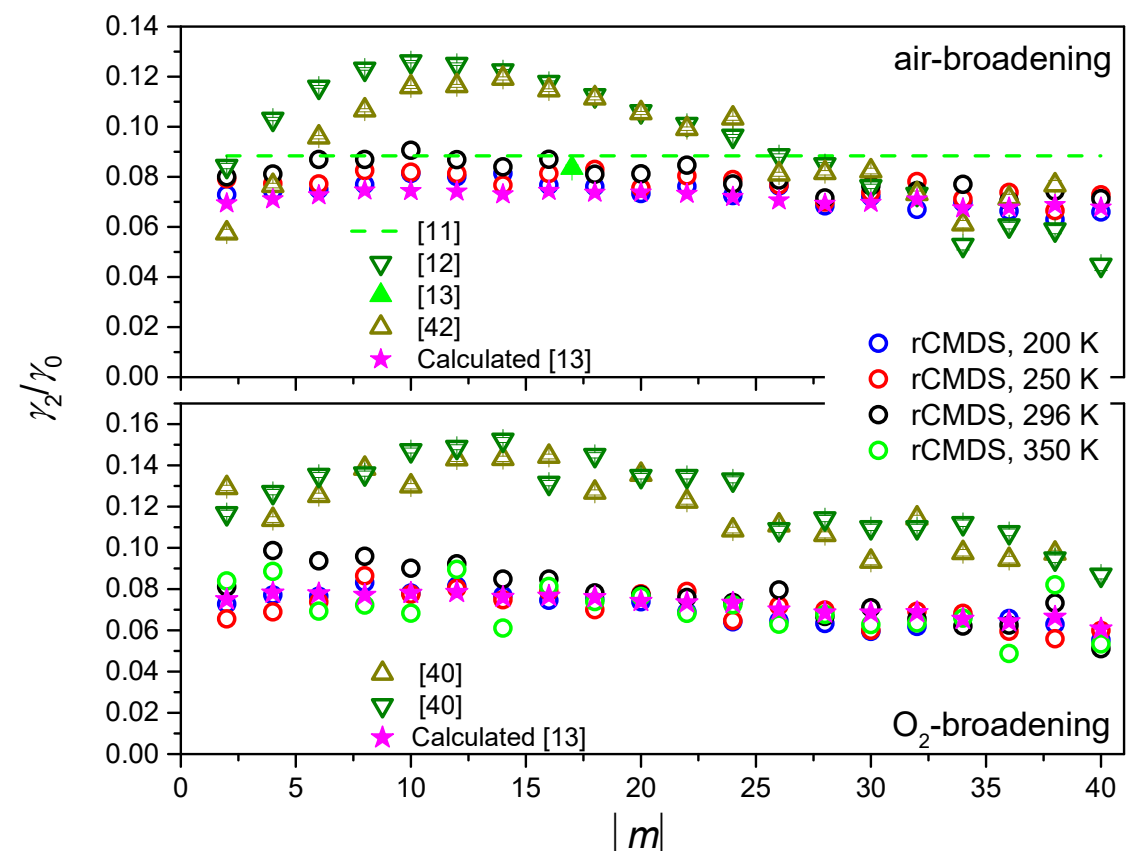

Fig. 5: Bottom panel: the ratio $\gamma_{2} / \gamma_{0}$ predicted by fitting the $r C M D S$-calculated spectra of $\mathrm{CO}_{2} / \mathrm{O}_{2}$ with the sdNG profile, obtained at $200 \mathrm{~K}, 250 \mathrm{~K}, 296 \mathrm{~K}$ and $350 \mathrm{~K}$ and comparison with the temperatureindependent values of [40] (olive and dark yellow triangles) obtained from fits of measured spectra with the sdV profile. The temperature-independent values, calculated using Eq. (1) [13] and our temperature exponents (magenta stars) are also shown.

Top panel: the rCMDS-predicted $\gamma_{2} / \gamma_{0}$ values for $\mathrm{CO}_{2} /$ air, associated with the sdNG profile and comparison with experimental values of [11] (dash green line), [13] (green triangle) and [12,42] (green and dark yellow triangles) obtained respectively with the pcsdNG, sdNG and sdV profiles. The temperature-independent values, calculated using Eq. (1) [13] and our temperature exponents (magenta stars) are also shown.

As for $\gamma_{0}$, the temperature dependences for $\gamma_{2}$ are also modeled by the power law. From values of $\gamma_{2}$ predicted by rCMDS at various temperatures, $n_{\gamma_{2}}$ for $\mathrm{O}_{2}$ - and air-broadening are thus deduced and plotted in Fig. 6, together with their statistical uncertainty obtained from the fits. For comparison, the rCMDS-predicted values for $n_{\gamma_{0}}$ (see Fig. 4) are also displayed. For $\mathrm{O}_{2}$ broadening, the values of $n_{\gamma_{2}}$ are determined with large uncertainty and randomly vary between the 0.05-1.2 range. For air-broadening, the variation with $|\mathrm{m}|$ of $n_{\gamma_{2}}$ is much less random. It is clearly shown that for $\mathrm{CO}_{2}$ in air, the temperature dependence of $\gamma_{2}$ is weaker than that of $\gamma_{0}$, which is consistent with the observation of [14] for $\mathrm{CO}_{2}$ in $\mathrm{N}_{2}$. This difference with Eq. (1) shows the limit of the phenomenological quadratic speed dependence and probably also of the 
power law for the temperature dependence. These models should thus be considered as effective with different temperature dependences for $\gamma_{0}$ and $\gamma_{2}$.

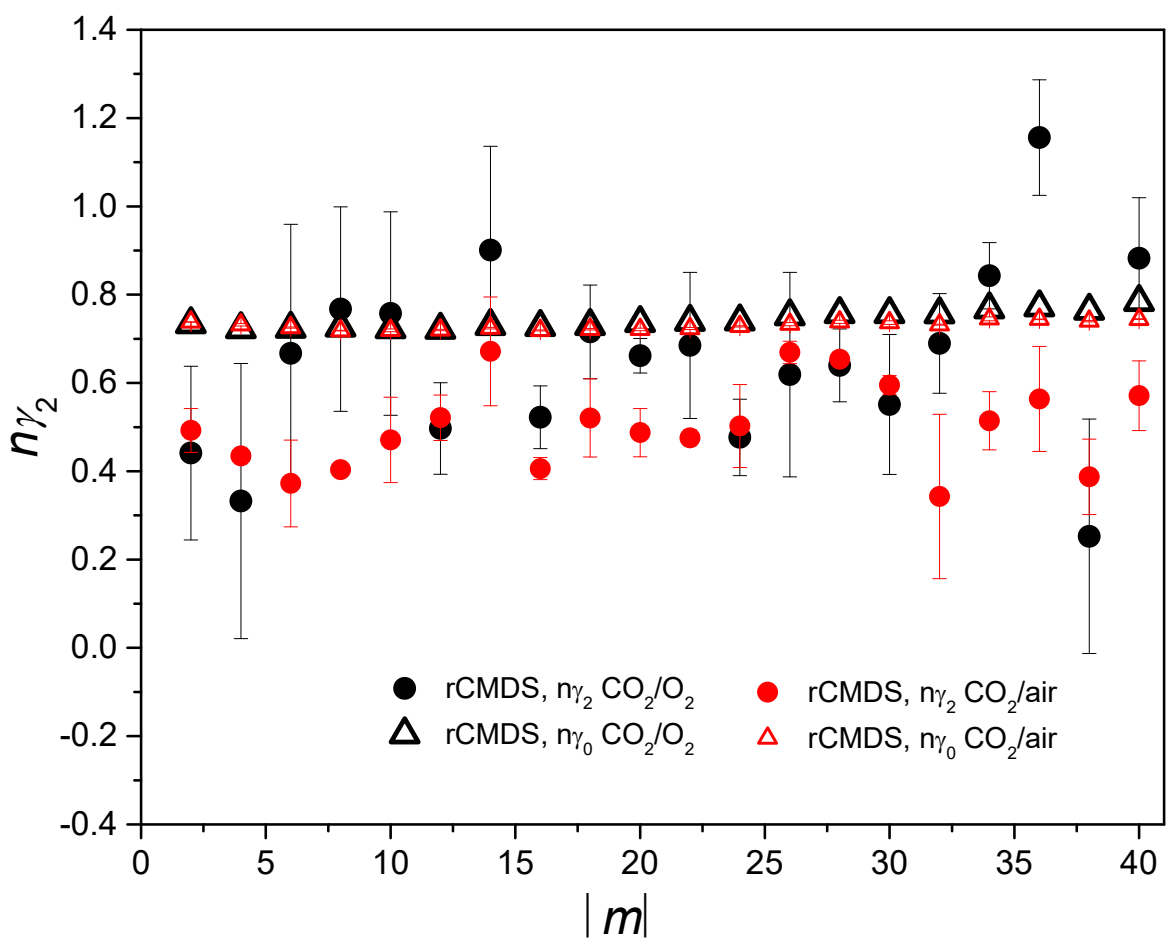

Fig. 6. The temperature exponents of the speed dependence parameters, $n_{\gamma_{2}}$, for $\mathrm{O}_{2^{-}}$(red circles) and air-broadened (black circles) $\mathrm{CO}_{2} . n_{\gamma_{0}}$ are also displayed for comparison. The plotted error bars correspond to the uncertainty $(1 \sigma)$ obtained from the fits of the temperature exponents.

\subsection{The Dicke narrowing parameter and its temperature dependence}

The retrieved Dicke narrowing parameters, $\beta$, for all the considered temperatures are presented in the left panel of Fig. 7 for both $\mathrm{CO}_{2} / \mathrm{O}_{2}$ and $\mathrm{CO}_{2} /$ air. Recall that results for $\mathrm{CO}_{2}$ in air were determined from results for $\mathrm{CO}_{2} / \mathrm{O}_{2}$ obtained in this work and those for $\mathrm{CO}_{2} / \mathrm{N}_{2}$, from this work and from [16]. It is well known that the Dicke narrowing coefficient strongly depends on the line-shape model used to fit the measured/simulated spectra. For the same line, values obtained with the Nelkin-Ghatak, the speed-dependent Nelkin-Ghatak and the partiallycorrelated speed-dependent Nelkin-Ghatak profiles could be completely different. To the best of our knowledge, there is no available data for $\beta$, obtained with the sdNG profile for $\mathrm{O}_{2}$ - and air-broadened $\mathrm{CO}_{2}$, except [13] in which no value of $\beta$ can be found. The rCMDS-predicted values of $\beta$ (left panel of Fig. 7) are rather small compared to those of $\gamma_{0}$ and $\gamma_{2}$. In fact, as can be observed in Fig. 1, including the Dicke narrowing effect improves only slightly the fit residuals. The determined values are small and largely influenced by the signal to noise ratio of the calculated spectra. The $1 \sigma$ combined uncertainty for $\beta$ is about $10-20 \%$. As a consequence, the deduced temperature dependence of the Dicke narrowing parameter, $n_{\beta}$, is associated with large error bars (right panel of Fig. 7). The values of $n_{\beta}$ from [14], determined from fits of measured spectra with the sdNG profile, but for $\mathrm{CO}_{2} / \mathrm{N}_{2}$ are also reported here for comparison. 

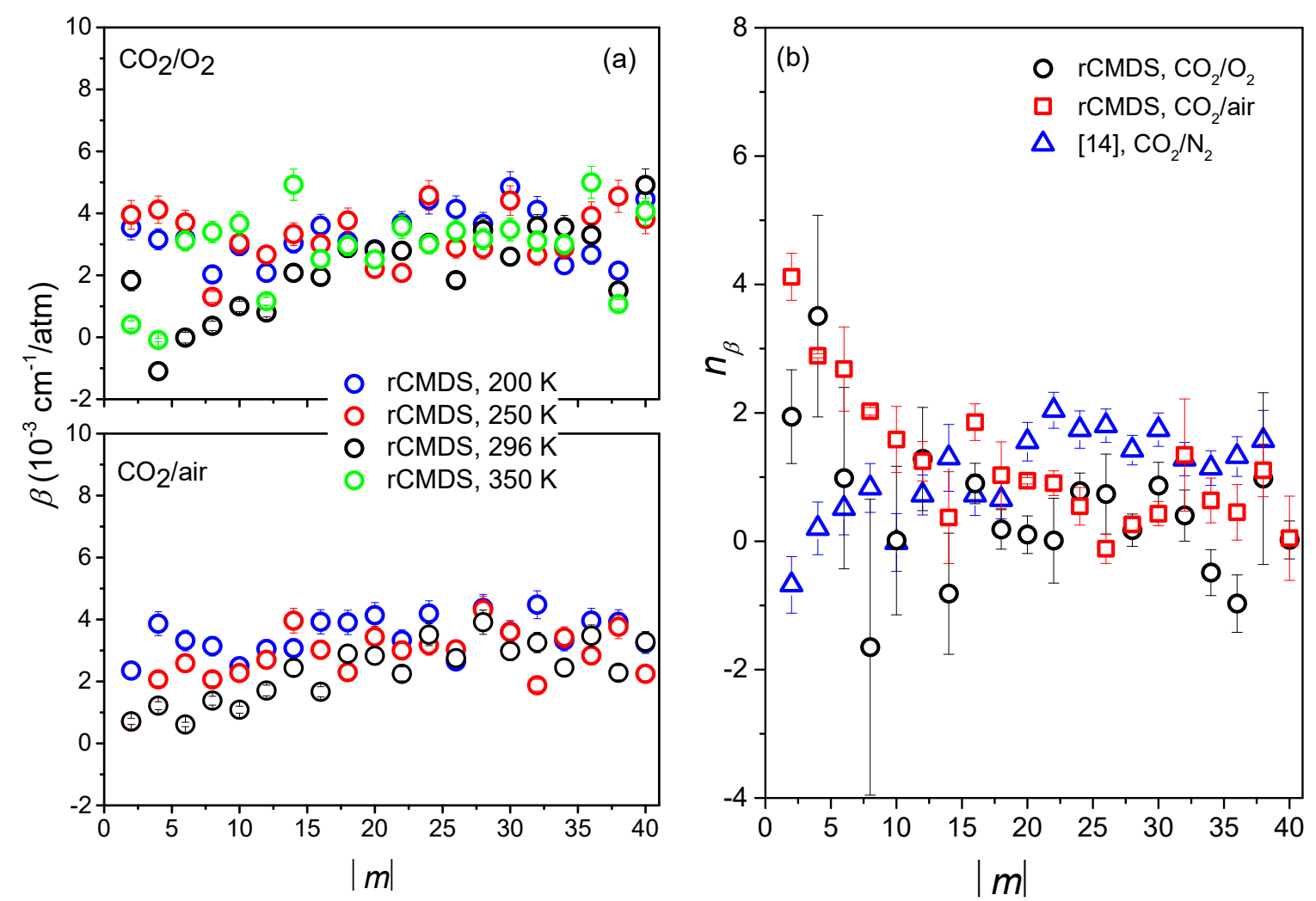

Fig. 7: Left panel: the rCMDS-predicted Dicke narrowing parameters for $\mathrm{O}_{2}$ and air-broadened $\mathrm{CO}_{2}$ for all the considered temperatures.

Right panel: the deduced temperature exponents of the Dicke narrowing parameters for $\mathrm{O}_{2}$-and airbroadened $\mathrm{CO}_{2}$ lines and comparison with measurement-deduced values of [14] for $\mathrm{CO}_{2} / \mathrm{N}_{2}$.

\subsection{The first-order line-mixing parameter and its temperature dependence}

Line-mixing effect in $\mathrm{CO}_{2}$ spectra is of great importance for applications such as atmospheric remote sensing studies (see $[47,48]$ for instance). Various studies were devoted to the calculations and/or measurements of either the first-order line-mixing coefficients or the off-diagonal elements of the relaxation matrix for $\mathrm{CO}_{2}$ (e.g. $[11,12,14,42,48]$. The rCMDS predicted first-order line-mixing parameters, $\zeta$, for $\mathrm{O}_{2}$-broadened $\mathrm{CO}_{2}$ for the four considered temperatures are plotted in the left part of Fig. 8. For air-broadened $\mathrm{CO}_{2}$, the values of $\zeta$ were determined as a combination of those for $\mathrm{O}_{2}$ - and $\mathrm{N}_{2}$-broadening [16] and are shown in the right part of Fig. 8. Our predicted values are compared with measured values of [49] for the $30012 \leftarrow 00001$ and $30013 \leftarrow 00001$ bands, obtained with the sdV profile and with those of [11] for the $30012 \leftarrow 00001$ band, with the pcsdNG profile. The first-order line-mixing parameters deduced from the modeled relaxation matrix of [48] at 296 and $200 \mathrm{~K}$ for the $v_{3}$ band are also displayed for comparison. For $|m| \leq 30$ a very good agreement with the measured values is observed while for higher values of $|m|$, the rCMDS-predicted values are larger than the measured and calculated values. Note that the difference with measured values cannot be explained by the difference in the used line profiles since it was observed that the first-order line-mixing parameter does not significantly depend on the line shape (see $[38,49]$ for instance). A possible source of difference could be our requantization scheme. In fact, in the requantization procedure used in our CMDS, we did not take into account the centrifugal distortion effect. As a result, the successive $P(J)$ lines are equally spaced in the rCMDScalculated spectra, which is not the case for a vibrational band of $\mathrm{CO}_{2}$. Furthermore, as 
explained in [18], the requantization is based on a single $P$ line criterion. As a result, the calculated $R$ branch spectrum is the exact symmetric of the $P$ branch. We thus disregarded the direction in which molecules rotate, the line-mixing process can be badly taken into account.

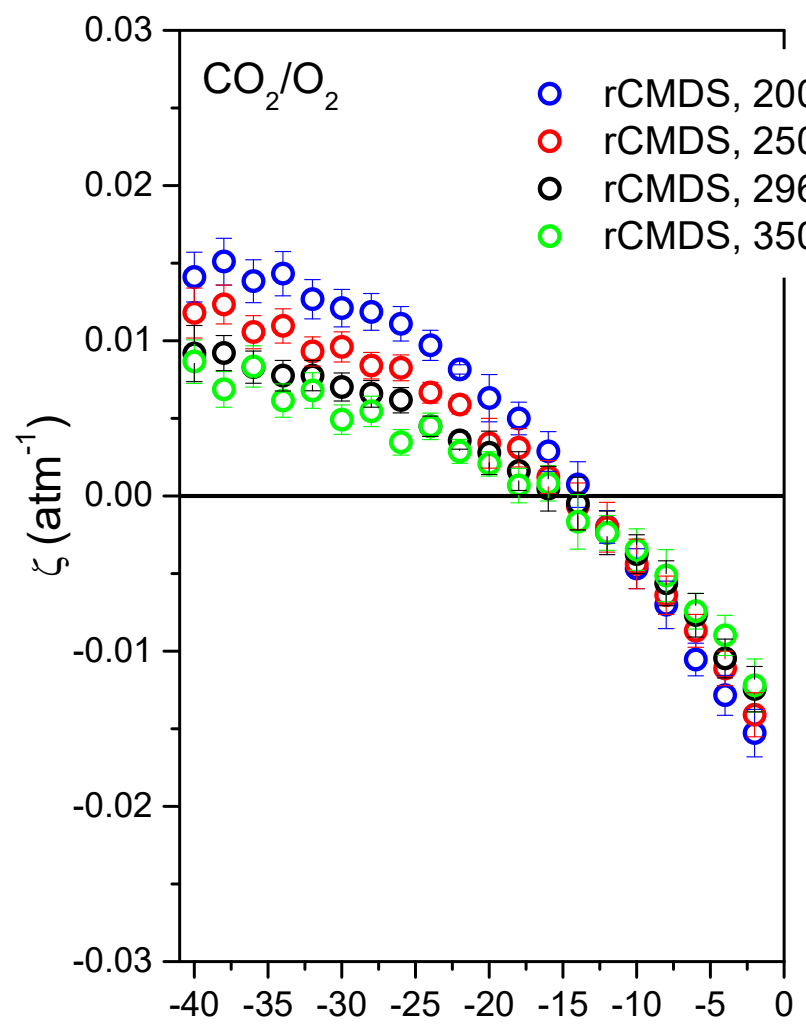

$m$

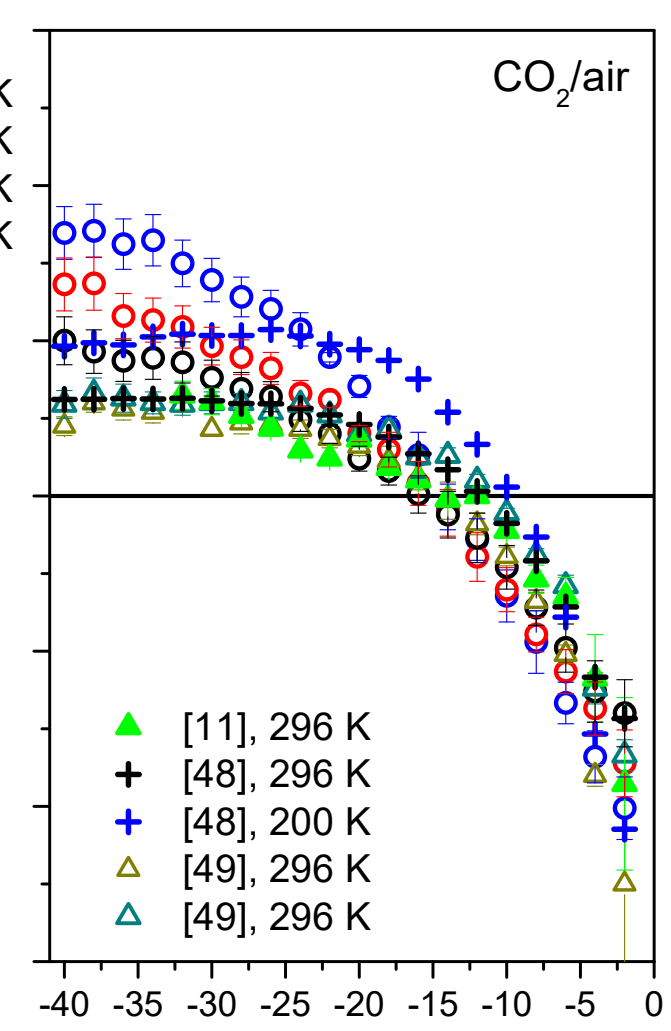

$m$

Fig.8: Left panel: first-order line-mixing parameters predicted from $r C M D S$ for $\mathrm{O}_{2}$-broadened $\mathrm{CO}_{2}$ at 200, 250, 296 and $350 \mathrm{~K}$.

Right panel: air-broadened first-order line-mixing parameters for $\mathrm{CO}_{2}$, calculated from the present rCMDS-predicted values for $\mathrm{CO}_{2} / \mathrm{O}_{2}$ and those of $\mathrm{CO}_{2} / \mathrm{N}_{2}$ [16] at 200, 250 and $296 \mathrm{~K}$. Measured values for $\mathrm{CO}_{2}$ in air of [49] for the $30012 \leftarrow 00001$ (dark cyan) and 30013 $\leftarrow 0001$ (dark yellow) bands, obtained with the sdV profile and those of [11] for the (30012 $\leftarrow 0001)$ band, with the pcsdNG profile are reported for comparison. Values deduced from the modeled relaxation matrix of [48] for the $v_{3}$ band at 296 and $200 \mathrm{~K}$ are also displayed.

The temperature dependence of the rCMDS-predicted $\zeta$ is presented in Fig. 9 for both $\mathrm{CO}_{2} / \mathrm{O}_{2}$ and $\mathrm{CO}_{2}$ /air. The plotted error bar is the uncertainty due to the fit of the temperature exponents which take the uncertainty of $\zeta(T)$ into account. As can be observed, there is no significant difference between $n_{\zeta}$ for $\mathrm{O}_{2}$ - and air-broadening and they are in good agreement with the experimental values of [14] for $\mathrm{CO}_{2}$ in $\mathrm{N}_{2}$. 


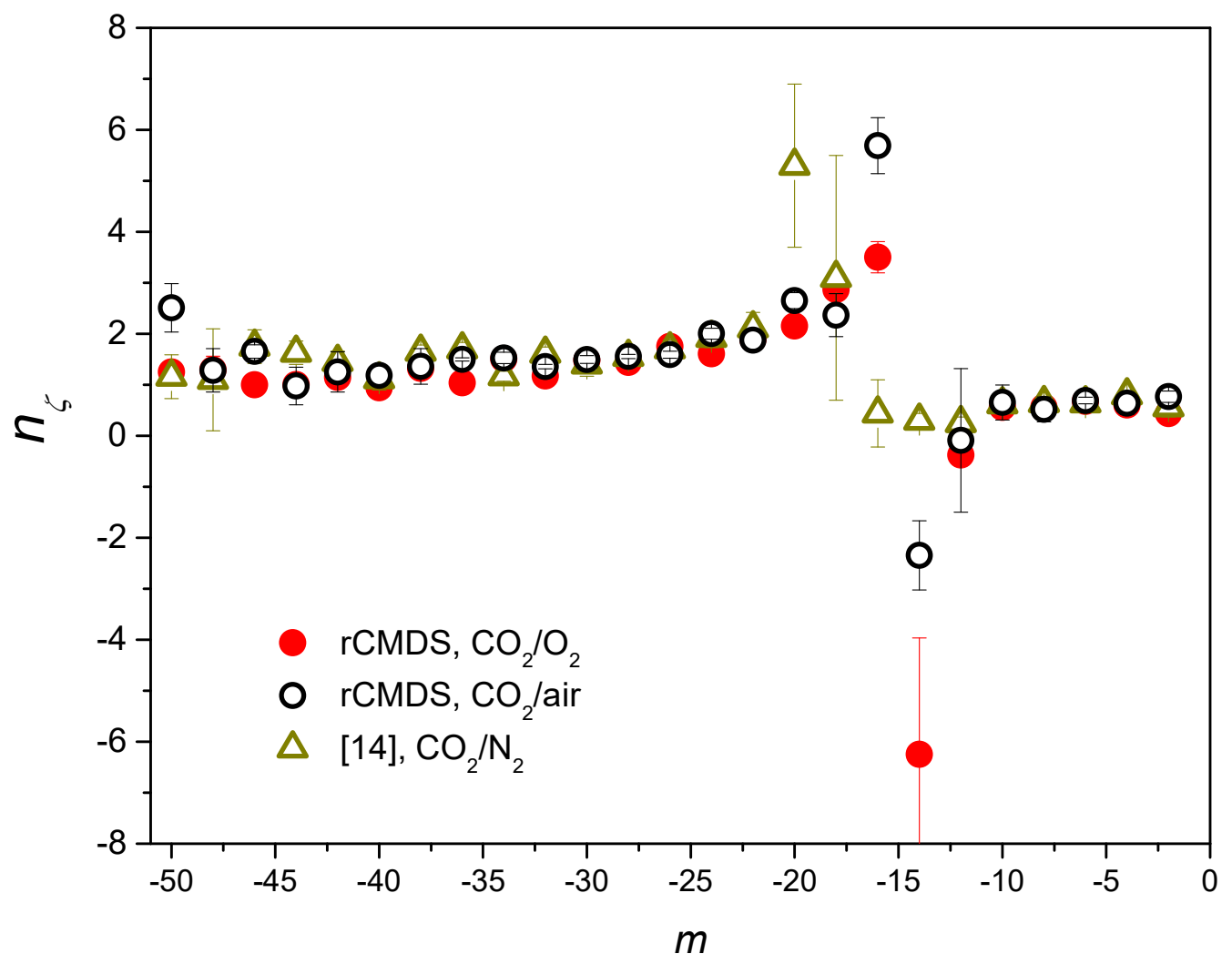

Fig.9: The temperature dependences of the first-order line-mixing parameters predicted by rCMDS for $\mathrm{CO}_{2} / \mathrm{O}_{2}$ and $\mathrm{CO}_{2} /$ air. Values of [14] for $\mathrm{CO}_{2} / \mathrm{N}_{2}$ are also displayed for comparison.

\section{Conclusions}

Line-shape parameters for $\mathrm{O}_{2}$-broadened $\mathrm{CO}_{2}$ transitions were predicted using requantized classical molecular dynamics simulations. Spectra were simulated for four temperature conditions, from the near Doppler regime to the collisional one. The various collisional effects affecting the line profile are thus included in the simulated spectra. Lineshape parameters were deduced by fitting the simulated spectra with the quadratic speeddependent Nelkin-Ghatak profile. The collisional broadening coefficient, its speed dependence, the Dicke narrowing and the first-order line-mixing parameters were retrieved using a multispectrum fitting procedure. The temperature dependences of these parameters were obtained using the usual single power law. The obtained parameters for $\mathrm{CO}_{2} / \mathrm{O}_{2}$ were then combined with those of $\mathrm{CO}_{2} / \mathrm{N}_{2}$, predicted using rCMDS in our previous study [16] to deduce parameters for $\mathrm{CO}_{2}$ in air. Comparison of the predicted parameters, their temperature dependences for both $\mathrm{CO}_{2} / \mathrm{O}_{2}$ and $\mathrm{CO}_{2} /$ air with measured data show very good agreement. This shows that rCMDS can be used as a powerful tool, complementary to high quality measurements, to address the precision and accuracy requirements of application such as atmospheric remote sensing as well as for populating spectroscopic databases with refined line-shape parameters.

\section{Acknowledgments}

This work was granted access to the HPC resources of IDRIS under the allocation 2019A0060907520 made by GENCI. The authors from Hanoi National University of Education (HNUE) are pleased to acknowledge the financial support of this research by the National 
Foundation for Science and Technology Development (NAFOSTED) of Vietnam under grant number of 103.03-2018.09. 


\begin{tabular}{|c|c|c|c|c|c|c|c|c|c|c|c|c|c|c|c|c|}
\hline Line & $\gamma_{0}$ & unc & $\gamma_{2}$ & unc & $\beta$ & Unc & $\zeta$ & unc & $n_{\gamma_{0}}$ & $u n c$ & $n_{\gamma_{2}}$ & unc & $n_{\beta}$ & unc & $n_{\zeta}$ & unc \\
\hline $\mathrm{P} 2$ & 0.0778 & 3.8 & 0.0063 & 3.2 & 0.0018 & 3.3 & -0.0124 & 14.5 & 0.732 & 1.6 & 0.441 & 196 & 1.940 & 730 & 0.436 & 57 \\
\hline P4 & 0.0742 & 3.7 & 0.0073 & 3.7 & -0.0011 & 2.4 & -0.0105 & 12.6 & 0.726 & 4.6 & 0.333 & 312 & 3.508 & 1571 & 0.603 & 49 \\
\hline P6 & 0.0720 & 3.6 & 0.0068 & 3.4 & 0.0000 & 1.7 & -0.0077 & 14.1 & 0.722 & 3.6 & 0.667 & 292 & 0.983 & 1413 & 0.675 & 80 \\
\hline P8 & 0.0704 & 3.5 & 0.0068 & 3.4 & 0.0004 & 1.5 & -0.0056 & 14.5 & 0.725 & 2.8 & 0.767 & 231 & -1.651 & 2305 & 0.562 & 41 \\
\hline $\mathrm{P} 10$ & 0.0690 & 3.5 & 0.0062 & 3.1 & 0.0010 & 1.7 & -0.0038 & 12.5 & 0.724 & 3.5 & 0.757 & 230 & 0.011 & 1156 & 0.558 & 71 \\
\hline $\mathrm{P} 12$ & 0.0678 & 3.4 & 0.0063 & 3.1 & 0.0008 & 1.3 & -0.0024 & 14.0 & 0.720 & 3.0 & 0.497 & 104 & 1.282 & 804 & -0.375 & 124 \\
\hline P14 & 0.0666 & 3.3 & 0.0057 & 2.8 & 0.0021 & 2.3 & -0.0005 & 17.0 & 0.730 & 2.6 & 0.901 & 235 & -0.817 & 943 & -6.247 & 2281 \\
\hline P16 & 0.0657 & 3.3 & 0.0056 & 2.8 & 0.0020 & 2.4 & 0.0005 & 14.5 & 0.726 & 2.3 & 0.522 & 71 & 0.899 & 314 & 3.503 & 306 \\
\hline P18 & 0.0647 & 3.2 & 0.0051 & 2.5 & 0.0029 & 3.0 & 0.0016 & 12.5 & 0.730 & 3.7 & 0.716 & 106 & 0.184 & 308 & 2.865 & 192 \\
\hline $\mathrm{P} 20$ & 0.0640 & 3.2 & 0.0049 & 2.5 & 0.0028 & 2.9 & 0.0028 & 13.8 & 0.734 & 3.4 & 0.662 & 39 & 0.103 & 293 & 2.151 & 143 \\
\hline $\mathrm{P} 22$ & 0.0633 & 3.2 & 0.0048 & 2.4 & 0.0028 & 2.9 & 0.0036 & 5.6 & 0.739 & 1.7 & 0.685 & 166 & 0.009 & 660 & 1.894 & 125 \\
\hline $\mathrm{P} 24$ & 0.0626 & 3.1 & 0.0046 & 2.3 & 0.0030 & 3.1 & 0.0045 & 6.5 & 0.741 & 5.3 & 0.477 & 87 & 0.779 & 283 & 1.609 & 153 \\
\hline P26 & 0.0621 & 3.1 & 0.0049 & 2.5 & 0.0018 & 2.1 & 0.0062 & 8.2 & 0.749 & 5.1 & 0.619 & 231 & 0.735 & 623 & 1.752 & 168 \\
\hline P28 & 0.0615 & 3.1 & 0.0041 & 2.1 & 0.0035 & 3.6 & 0.0066 & 8.6 & 0.756 & 4.5 & 0.640 & 83 & 0.172 & 251 & 1.440 & 40 \\
\hline P30 & 0.0611 & 3.1 & 0.0043 & 2.2 & 0.0026 & 2.9 & 0.0070 & 9.1 & 0.757 & 4.8 & 0.551 & 158 & 0.866 & 362 & 1.478 & 124 \\
\hline P32 & 0.0606 & 3.0 & 0.0040 & 2.0 & 0.0036 & 3.8 & 0.0078 & 9.8 & 0.760 & 3.6 & 0.690 & 113 & 0.401 & 399 & 1.173 & 65 \\
\hline P34 & 0.0602 & 3.0 & 0.0037 & 1.9 & 0.0036 & 3.8 & 0.0078 & 9.8 & 0.766 & 7.4 & 0.843 & 75 & -0.489 & 358 & 1.505 & 80 \\
\hline P36 & 0.0597 & 2.9 & 0.0037 & 1.9 & 0.0033 & 3.6 & 0.0083 & 10.4 & 0.771 & 5.7 & 1.156 & 131 & -0.971 & 447 & 1.038 & 136 \\
\hline P38 & 0.0594 & 2.9 & 0.0044 & 2.2 & 0.0015 & 2.4 & 0.0092 & 11.3 & 0.763 & 4.2 & 0.253 & 266 & 0.976 & 1339 & 1.322 & 113 \\
\hline P40 & 0.0589 & 2.9 & 0.0030 & 1.6 & 0.0049 & 5.2 & 0.0092 & 18.1 & 0.777 & 4.0 & 0.883 & 137 & 0.020 & 295 & 0.942 & 88 \\
\hline P42 & 0.0585 & 2.9 & 0.0034 & 1.7 & 0.0037 & 4.1 & 0.0103 & 12.4 & 0.773 & 3.1 & 0.927 & 156 & -0.751 & 797 & 1.146 & 110 \\
\hline P44 & 0.0582 & 2.9 & 0.0031 & 1.7 & 0.0046 & 5.0 & 0.0094 & 11.5 & 0.768 & 4.1 & 0.405 & 568 & 1.476 & 1608 & 1.003 & 175 \\
\hline P46 & 0.0577 & 2.9 & 0.0034 & 1.7 & 0.0034 & 4.1 & 0.0113 & 13.5 & 0.768 & 4.0 & -0.083 & 1131 & & & 0.999 & 186 \\
\hline P48 & 0.0573 & 2.9 & 0.0032 & 1.7 & 0.0040 & 4.8 & 0.0094 & 11.6 & 0.778 & 5.9 & 0.335 & 368 & 0.158 & 993 & 1.293 & 267 \\
\hline P50 & 0.0570 & 2.9 & 0.0031 & 1.7 & 0.0053 & 6.2 & 0.0109 & 13.1 & 0.786 & 18.4 & 0.863 & 942 & 0.224 & 3603 & 1.249 & 175 \\
\hline
\end{tabular}

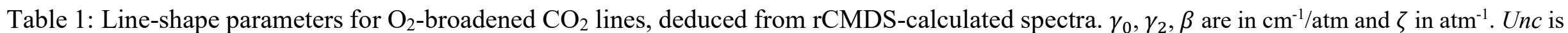
the total uncertainty $(1 \sigma)$, in units of the last quoted digit. 


\begin{tabular}{|c|c|c|c|c|c|c|c|c|c|c|c|c|c|c|c|c|}
\hline Line & $\gamma_{0}$ & $u n c$ & $\gamma_{2}$ & $u n c$ & $\beta$ & unc & $\zeta$ & unc & $n_{\gamma_{0}}$ & $u n c$ & $n_{\gamma_{2}}$ & unc & $n_{\beta}$ & unc & $n_{\zeta}$ & unc \\
\hline $\mathrm{P} 2$ & 0.0883 & 4.4 & 0.0071 & 3.5 & 0.0007 & 0.7 & -0.0140 & 21.7 & 0.738 & 0.5 & 0.484 & 49.5 & 3.989 & 366 & 0.767 & 111 \\
\hline $\mathrm{P} 4$ & 0.0838 & 4.2 & 0.0068 & 3.4 & 0.0012 & 1.2 & -0.0126 & 19.8 & 0.732 & 4.3 & 0.515 & 1.0 & 2.367 & 30 & 0.640 & 219 \\
\hline P6 & 0.0815 & 4.1 & 0.0071 & 3.5 & 0.0006 & 0.6 & -0.0098 & 15.5 & 0.726 & 2.0 & 0.374 & 98.3 & 2.683 & 656 & 0.689 & 62 \\
\hline P8 & 0.0798 & 4.0 & 0.0069 & 3.5 & 0.0014 & 1.3 & -0.0072 & 11.4 & 0.718 & 1.1 & 0.406 & 0.5 & 1.996 & 594 & 0.517 & 243 \\
\hline $\mathrm{P} 10$ & 0.0783 & 3.9 & 0.0071 & 3.5 & 0.0011 & 1.0 & -0.0046 & 14.0 & 0.719 & 4.9 & 0.472 & 96.8 & 1.501 & 515 & 0.653 & 342 \\
\hline P12 & 0.0769 & 3.8 & 0.0067 & 3.3 & 0.0017 & 1.7 & -0.0027 & 16.0 & 0.720 & 2.5 & 0.532 & 51.6 & 1.151 & 308 & -0.089 & 1408 \\
\hline P14 & 0.0757 & 3.8 & 0.0064 & 3.2 & 0.0024 & 2.4 & -0.0012 & 15.0 & 0.724 & 3.0 & 0.694 & 123.3 & 0.259 & 716 & -2.345 & 680 \\
\hline P16 & 0.0748 & 3.7 & 0.0065 & 3.2 & 0.0017 & 1.7 & 0.0001 & 12.0 & 0.719 & 1.9 & 0.403 & 24.9 & 1.851 & 285 & 5.691 & 549 \\
\hline P18 & 0.0739 & 3.7 & 0.0060 & 3.0 & 0.0029 & 2.8 & 0.0016 & 9.0 & 0.722 & 2.2 & 0.532 & 88.5 & 0.984 & 519 & 2.366 & 423 \\
\hline P20 & 0.0731 & 3.7 & 0.0059 & 3.0 & 0.0028 & 2.8 & 0.0024 & 8.0 & 0.721 & 4.4 & 0.476 & 54.5 & 0.992 & 48 & 2.650 & 157 \\
\hline $\mathrm{P} 22$ & 0.0724 & 3.6 & 0.0061 & 3.1 & 0.0022 & 2.2 & 0.0040 & 6.2 & 0.723 & 3.7 & 0.458 & 17.9 & 0.997 & 192 & 1.876 & 182 \\
\hline P24 & 0.0717 & 3.6 & 0.0055 & 2.8 & 0.0035 & 3.5 & 0.0049 & 7.5 & 0.728 & 2.0 & 0.542 & 94.1 & 0.406 & 294 & 2.002 & 107 \\
\hline P26 & 0.0711 & 3.6 & 0.0056 & 2.8 & 0.0028 & 2.7 & 0.0064 & 9.7 & 0.733 & 5.4 & 0.664 & 25.3 & -0.070 & 228 & 1.593 & 67 \\
\hline P28 & 0.0704 & 3.5 & 0.0050 & 2.5 & 0.0039 & 3.9 & 0.0069 & 10.5 & 0.738 & 5.3 & 0.627 & 16.5 & 0.365 & 92 & 1.555 & 40 \\
\hline P30 & 0.0700 & 3.5 & 0.0054 & 2.7 & 0.0030 & 2.9 & 0.0076 & 11.6 & 0.737 & 6.0 & 0.595 & 21.6 & 0.383 & 189 & 1.496 & 76 \\
\hline P32 & 0.0695 & 3.5 & 0.0052 & 2.6 & 0.0033 & 3.2 & 0.0086 & 13.2 & 0.732 & 1.9 & 0.412 & 186.2 & 1.026 & 874 & 1.358 & 44 \\
\hline P34 & 0.0690 & 3.5 & 0.0053 & 2.7 & 0.0025 & 2.4 & 0.0089 & 13.8 & 0.745 & 6.6 & 0.510 & 65.9 & 0.650 & 349 & 1.527 & 111 \\
\hline P36 & 0.0684 & 3.4 & 0.0048 & 2.4 & 0.0035 & 3.4 & 0.0087 & 13.2 & 0.744 & 1.0 & 0.549 & 118.9 & 0.535 & 432 & 1.498 & 32 \\
\hline P38 & 0.0680 & 3.4 & 0.0051 & 2.5 & 0.0023 & 2.2 & 0.0093 & 14.0 & 0.740 & 2.2 & 0.334 & 85.5 & 1.352 & 411 & 1.362 & 349 \\
\hline P40 & 0.0676 & 3.4 & 0.0048 & 2.4 & 0.0033 & 3.2 & 0.0100 & 15.4 & 0.744 & 0.5 & 0.514 & 78.9 & 0.372 & 656 & 1.184 & 205 \\
\hline P42 & 0.0670 & 3.4 & 0.0042 & 2.1 & 0.0047 & 4.7 & 0.0111 & 16.9 & 0.756 & 5.9 & 0.954 & 72.6 & -1.170 & 526 & 1.252 & 394 \\
\hline P44 & 0.0667 & 3.3 & 0.0046 & 2.3 & 0.0033 & 3.2 & 0.0105 & 16.3 & 0.730 & 4.4 & 0.214 & 147.1 & 1.798 & 282 & 0.978 & 368 \\
\hline P46 & 0.0661 & 3.3 & 0.0043 & 2.1 & 0.0033 & 3.3 & 0.0107 & 15.8 & 0.734 & 5.8 & -0.319 & 347.0 & 3.393 & 473 & 1.653 & 131 \\
\hline P48 & 0.0659 & 3.3 & 0.0047 & 2.3 & 0.0023 & 2.2 & 0.0107 & 16.7 & 0.743 & 11.7 & 0.409 & 9.8 & 1.389 & 39 & 1.284 & 424 \\
\hline P50 & 0.0655 & 3.3 & 0.0044 & 2.2 & 0.0036 & 3.5 & 0.0108 & 16.4 & 0.726 & 5.9 & 0.924 & 180.8 & 0.231 & 998 & 2.510 & 475 \\
\hline
\end{tabular}

Table 2: The same as Table 1 but for air-broadened $\mathrm{CO}_{2}$. 


\section{References}

[1] Buchwitz M, de Beek R, Burrows JP, Bovensmann H, Warneke T, Notholt J, Meirink JF, Goede APH, Bergamaschi P, Korner S, Heimann M, Schulz A. Atmospheric methane and carbon dioxide from SCIAMACHY stallite data: initial comparison with chemistry and transport models. Atmos Chem Phys 2005;5:941-62.

[2] Butz A, Guerlet S, Hasekamp O, Schepers D, Galli A, Aben I, Frankenberg C, Hartmann JM, Tran H, Kuze A, Keppel-Aleks G, Toon G, Wunch D, Wennberg P, Deutscher N, Griffith D, Macatangay R, Messerschmidt J, Notholt J, Warneke T. Toward accurate $\mathrm{CO}_{2}$ and $\mathrm{CH}_{4}$ observations from GOSAT. Geophys Res Let 2011;38:L14812, doi:10.1029/2011GL047888.

[3] Crisp D. Measuring atmospheric carbon dioxide from space with the Orbing Carbon Observatory-2 (OCO-2). Proc SPIE 9607, Earth Observing Systems XX, 9607072, 2015 https://doi.org/10.1117/12.2187291

[4] Wunch D, Wennberg PO, Osterman G, Fisher B, Naylor B et al. Comparisons of the Orbiting Carbon Observatory-2 (OCO-2) x $\mathrm{CO}_{\mathrm{CO}}$ measurements with TCCON. Atmos Meas Tech 2017;10:2209-38.

[5] Miller CE, Brown LR, Toth RA, Benner DC, Malathy DV. Spectroscopic challenges for high accuracy retrievals of atmospheric $\mathrm{CO}_{2}$ and the Orbiting Carbon Observatory (OCO) experiment. C R Phys Acad Sci Paris 2005;6:876-87.

[6] Miller CE, Crisp D, DeCola PL, Olsen SC, Randerson JT, Michalak AM et al. Precision requirements for space-based XCO2 data. J Geophys Res, 2007;112:D10314, doi:10.1029/2006JD007659.

[7] Hartmann JM, Tran H, Armante R, Boulet C, Campargue A, Ciurylo R, Forget F, Gianfrani L, Gordon I, Guerlet S, Gustafsson M, Hodges J, Kassi S, Lisak D, Thibault F, Toon GC. Recent advances in collisional effects on spectra of molecular gases and their pratical consequences. J Quant Spectrosc Radiat Transfer 2018;213:178-227.

[8] Long DA, Bielska K, Lisak D, Havey DK, Okumura M, Miller CE, Hodges JT. The air-broadened, near-infrared $\mathrm{CO}_{2}$ line shape in the spectrally isolated regime: Evidence of simultaneous Dicke narrowing and speed dependence. J Chem Phys 2011;135:064308.

[9] Bui TQ, Long DA, Cygan A, Sironneau VT, Hogan DW, Rupasinghe PM, Ciurylo R, Lisak D, Okumura M. Observations of Dicke narrowing and speed dependence in air-broadened $\mathrm{CO}_{2}$ lineshapes near $2.06 \mu \mathrm{m}$. J Chem Phys 2014;141:174301.

[10] Lin H , Reed ZD , Sironneau VT , Hodges JT . Cavity ring-down spectrometer for high-fidelity molecular absorption measurements. J Quant Spectrosc Radiat Transf 2015;161:11-20.

[11] Long DA, Wojtewicz S, Miller CE, Hodges JT. Frequency-agile, rapid scanning cavity ring-down spectrosocpy (FARS-CRDS) measurements of the $(30012) \leftarrow(00001)$ mear-infrared carbon dioxide band. J Quant Spectrosc Rad Transf 2015;161:35-40.

[12] Benner DC, Devi VM, Sung K, et al. Line parameters including temperature dependences of airand self-broadened line shapes of ${ }^{12} \mathrm{C}^{16} \mathrm{O}_{2}$ : 2.06- $\mu \mathrm{m}$ region. J Mol Spectrosc 2016;326:31-47.

[13] Ghysels M, Liu Q, Fleisher AJ, Hodges JT. A variable-temperature cavity ring-down spectrometer with application to line shape analysis of $\mathrm{CO}_{2}$ spectra in the $1600 \mathrm{~nm}$ region. Appl Phys B 2017;123124:1-13.

[14] Wilzewski JS, Birk M, Loos J, Wagner G. Temperature-Dependence Laws of Absorption Line Shape Parameters of the $\mathrm{CO}_{2} v_{3}$ Band. J Quant Spectrosc Rad Transfer 2018;206:296-305.

[15] Benner DC, Rinsland CP, Devi VM, Smith MAH, Atkins D. A multispectrum nonlinear least squares fitting technique. J Quant Spectrosc Radiat Transfer 1995;53:705-21.

[16] Nguyen HT, Ngo NH, Tran H. Prediction of line shape parameters and their temperature dependences for $\mathrm{CO}_{2}-\mathrm{N}_{2}$ using molecular dynamics simulations. J Chem Phys 2018;149:224301. 
[17] Tran DD, Sironneau VT, Hodges JT, Armante R, Cuesta J, Tran H. Prediction of high-order lineshape parameters for air-broadened $\mathrm{O}_{2}$ lines using requantized classical molecular dynamics simulations and comparison with measurements. J Quant Spectrosc Rad Transfer 2019;222-223:108-14.

[18] Hartmann JM, Tran H, Ngo NH, Landsheere X, Chelin P, Lu Y, Liu AW, Hu SM, Gianfrani L, Casa G, Castrillo A, Lepère M, Delière Q, Dhyne M, Fissiaux L. Ab initio calculations of the spectral shapes of $\mathrm{CO}_{2}$ isolated lines including non-Voigt effects and comparisons with experiments. Phy Rev A 2013;87:013403.

[19] Larcher G, Tran H, Schwell M, Chelin P, Landsheere X, Hartmann JM. $\mathrm{CO}_{2}$ isolated line shapes by classical molecular dynamcis simulations: influence of the intermolecular potential and comparison with new measurements. J Chem Phys 2014;140:084308.

[20] Hartmann JM, Sironneau V, Boulet C, Svensson T, Hodges JT, Xu CT. Collisional broadening and spectral shapes of absorption lines of free and nanopore-confined $\mathrm{O}_{2}$ gas. Phys Rev A 2013;87:032510. doi:10.1103/PhysRevA.87.032510.

[21] Lamouroux J, Sironneau V, Hodges JT, Hartmann JM. Isolated line shapes of molecular oxygen: Requantized classical molecular dynamics calculations versus measurements. Phys Rev A 2014;89:042504. doi:10.1103/PhysRevA.89.042504.

[22] Ngo NH, Tran H, Gamache RR, Bermejo D, Doménech JL. Influence of velocity effects on the shape of $\mathrm{N}_{2}$ (and air) broadened $\mathrm{H}_{2} \mathrm{O}$ lines revisited with classical molecular dynamics simulations. $\mathrm{J}$ Chem Phys 2012;137:064302.

[23] Ngo NH, Tran H, Gamache RR. Pure $\mathrm{H}_{2} \mathrm{O}$ isolated line-shape modeling based on classical molecular dynamics simulations of velocity changes and semi-classical calculations of the speeddependent collisional parameters. J Chem Phys 2012;136:154310.

[24] Tran H, Ngo NH, Hartmann JM, Gamache RR, Mondelain D, Kassi S, Campargue A, Gianfrani L, Castrillo A, Rohart F. Velocity effect on the shape of pure $\mathrm{H}_{2} \mathrm{O}$ isolated lines: Complementary tests of the partially-Correlated Speed-Dependent Keilson-Storer model. J Chem Phys 2013;138:034302.

[25] Le T, Domenech JL, Lepère M, Tran H. Molecular dynamic simulations of $\mathrm{N}_{2}$-broadened methane line shapes and comparison with experiments. J Chem Phys 2017;146,094305.

[26] Tran H, Domenech JL. Spectral shapes of Ar-broadened HCl lines in the fundamental band by classical molecular dynamics simulations and comparison with experiments. J Chem Phys 2014;141:064313.

[27] Ngo NH, Hartmann JM. A strategy to complete databases with parameters of refined line shapes and its test for $\mathrm{CO}$ in $\mathrm{He}$, Ar and Kr. J Quant Spectrosc Radiat Transf 2017;203:334-40. doi:10.1016/j.jqsrt.2017.01.031.

[28] Murthy CS, O’Shea SF, McDonald IR. Electrostatic interactions in molecular crystals lattice dynamics of solid nitrogen and carbon dioxide. Mol Phys 1983;50:531-41.

[29] Bouanich JP. Site-site Lennard-Jones potential parameters for $\mathrm{N}_{2}, \mathrm{O}_{2}, \mathrm{H}_{2}, \mathrm{CO}$ and $\mathrm{CO}_{2}$. J Quant Spectrosc Radiat Transfer 1992;47:243-50.

[30] Hirschfelder JE, Curtiss CF, Bird RB, Molecular Theory of Gases and Liquids (Wiley, New York, 1954).

[31] Rosenkranz PK. Shape of the $5 \mathrm{~mm}$ oxygen band in the atmosphere. IEEE Trans Antennas Propag 1975;23:498-506.

[32] Ngo NH, Lisak D, Tran H, Hartmann JM. An isolated line-shape model to go beyond the Voigt profile in spectroscopic databases and radiative transfer codes. J Quant Spectrosc Rad Transf 2013;129:89-100.

[33] Rohart F, Mader H, Nicolaisen HW. Speed dependence of rotational relaxation induced by foreign gas collisions: studies on $\mathrm{CH}_{3} \mathrm{~F}$ by millimeter wave coherent transients. J Chem Phys 1994;101:647586. 
[34] Rohart F, Ellendt A, Kaghat K, Mäder H. Self and polar foreign gas line broadening and frequency shifting of $\mathrm{CH}_{3} \mathrm{~F}$ : effect of the speed dependence observed by millimeter-wave coherent transients. $\mathrm{J}$ Mol Spectrosc 1997;185:222-33.

[35] Nelkin M, Ghatak A. Simple binary collision model for Van Hove's Gs $(r, t)$, Phys Rev 1964;135:A4A9.

[36] Rautian SG, Sobel'man II. The effect of collisions on the Doppler broadening of spectral lines. Sov Phys Usp 1967;9:701-16.

[37] Delahaye T, Maxwell SE, Reed ZD, Lin H, Hodges JT, Sung K, Devi VM, Warneke T, Spietz P, Tran H. Precie methan absorption measurements in the $1.64 \mu \mathrm{m}$ spectral region for the MERLIN mission. J Geophys Res Atmos 2016;121:7360-70.

[38] Ngo NH, Lin H, Hodges JT, Tran H. Spectral shapes of rovibrational lines of CO broadened by He, $\mathrm{Ar}, \mathrm{Kr}$ and $\mathrm{SF}_{6}$ : A test case of the Hartmann-Tran profile. J Quant Spectrosc Rad Transfer 2017;203:325333.

[39] Tennyson J, Bernarth PF, Campargue A, Csaszar AG, Daumont L, Gamache RR, Hodges JT, Lisak D, Naumenko OV, Rothman LS, Tran H, Zobov NF, Buldyreva J, Boone CD, De Vizia MD, Gianfrani L, Hartmann JM, McPheat R, Weidmann D, Murray J, Ngo NH, Polyansky OL. Recommended isolatedline profile for representing high-resolution spectroscopic transitions (IUPAC technical report). Pure App Chem 2014;86:1931-43.

[40] Devi VM, Benner DC, Miller CE, Predoi-Cross A. Lorentz half-width, pressure-induced shift and speed-dependent coefficients in oxygen-broadened $\mathrm{CO}_{2}$ bands at 6227 and $6348 \mathrm{~cm}^{-1}$ using a constrained multispectrum analysis. J Quant Spectrosc Rad Transf 2010;111:2355-69.

[41] Hikida T, Yamada KMT. $\mathrm{N}_{2}$ - and $\mathrm{O}_{2}$-broadening of $\mathrm{CO}_{2}$ for the (300 1)III $\leftarrow(0000)$ band at 6231 $\mathrm{cm}^{-1}$. J Mol Spectrosc 2006;239:154-9.

[42] Devi VM, Benner DC, Sung K, Brown LR, Crawford TJ, Miller CE, Drouin BJ, Payne VH, Yu S, Smith MAH, Mantz AW, Gamache RR. Line parameters including temperature dependences of selfand air-broadened line shapes of ${ }^{12} \mathrm{C}^{16} \mathrm{O}_{2}: 1.6 \mu \mathrm{m}$ region. J Quant Spectrosc Rad Transf 2016;177:11744.

[43] Lisak D, Cygan A, Bermejo D, Domenech JL, Hodges JT, Tran H. Application of the HartmannTran profile to analysis of $\mathrm{H}_{2} \mathrm{O}$ spectra. J Quant Spectrosc Rad Transf 2015;164:221-30.

[44] Gordon IE, Rothman LS, Hill C, Kochanov RV, Tan Y, Bernath PF, Birk M, Boudon, CampargueA, Chance KV, Drouin BJ, Flaud JM, Gamache RR, Hodges JT, Jacquemart D, Perevalov VI, Perrin A, Shine KP, Smith MAH, Tennyson J, Toon GC, Tran H, Tyuterev VG, Barbe A, Császár AG, Devi VM, Furtenbacher T, Harrison JJ, Hartmann J-M, Jolly A, Johnson TJ, Karman T, Kleiner I, Kyuberis AA, Loos J, Lyulin OM, Massie ST, Mikhailenko SN, Moazzen-Ahmadi N, Müller HSP, Naumenko OV, Nikitin AV, Polyansky OL, Rey M, Rotger M, Sharpe SW, Sung K, Starikova E, Tashkun SA, Vander Auwera J, Wagner G, Wilzewski J, Wcisło P, Yu S, Zak EJ. The HITRAN2016 molecular spectroscopic database. J Quant Spectrosc Radiat Transf 2017;203:3-69. doi:10.1016/j.jqsrt.2017.06.038.

[45] Le T, Fissiaux L, Lepere M, Tran H. Isolated line shape of methane with various collision partners. J Quant Spectrosc Rad Transf 2016 ; 185 :27-36.

[46] Tran DD, Tran H, Vasilchenko S, Kassi S, Campargue A, Mondelain D. High sensitivity spectroscopy of the $\mathrm{O}_{2}$ band at $1.27 \mu \mathrm{m}$ : (II) air-broadened line profile parameters. J Quant Spectrosc Rad Transf 2019, in revision.

[47] Hartmann JM, Boulet C, Robert D. Collisional effects on molecular spectra. Laboratory experiments and model, consequences for applications. Elsevier, Amsterdam 2008.

[48] Lamouroux J, Régalia L, Thomas X, Vander Auwera J, Gamache RR, Hartmann JM. $\mathrm{CO}_{2}$ linemixing database and software update and its tests in the $2.1 \mu \mathrm{m}$ and $4.3 \mu \mathrm{m}$ regions. J Quant Spectrosc Rad Transfer 2015;151:88-96. 
[49] Predoi-Cross A, Liu W, Holladay C, Unni AV, Schofield I, McKellar ARW, Hurtmans D. Line profile study of transitions in the $30012 \leftarrow 00001$ and $30013 \leftarrow 00001$ bands of carbon dioxide perturbed by air. J Mol Spectrosc 2007;246:98-112. 